\title{
Comunicação participativa e mudança sociocultural
}

\section{Participatory communication and sociocultural change}

\section{Comunicación participativa y cambio sociocultural}

$\mathrm{H}$

á exatos dez anos, publicávamos o livro Relações públicas comunitárias: a comunicação em uma perspectiva dialógica e transformadora, coletânea que buscou resgatar o pensamento comunicacional brasileiro sobre essa temática e os aspectos históricos do florescimento das relações públicas comunitárias no Brasil, sinalizando novos aportes teóricos e as perspectivas críticas na concepção e nas práticas dessa área.

Foi no início da década de 1980 que se passou a encarar as relações públicas sob uma nova ótica, preconizando sua utilização também a serviço dos interesses populares e comunitários. Isto se deu graças ao avanço que então estava alcançando a comunicação popular alternativa, graças aos esforços empreendidos por defensores das liberdades democráticas e por associações como a Sociedade Brasileira de Estudos Interdisciplinares da Comunicação (Intercom) e a União Cristã Brasileira de Comunicação Social (UCBC). Estas promoviam ciclos de estudos e congressos, com debates voltados, sempre, para uma temática de resistência ao governo autoritário, numa conjuntura em que, desde 1964, o país vivia sob o regime militar. As frentes de lutas pela democracia, por parte da sociedade civil e dessas entidades de comunicação, colocavam em destaque as classes subalternas e os direitos humanos, apregoando a exigência de uma nova ordem para o campo da comunicação social.

As publicações nacionais aqui existentes na época e as que eram traduzidas, sobretudo as norte-americanas, enfatizavam predominantemente as técnicas e práticas no âmbito das empresas e dos governos. Assim, até por volta dos anos 1980, a literatura 
brasileira sobre relações públicas, por via de regra, era toda centrada em uma perspectiva pragmática e com a preocupação de como as organizações deviam se relacionar com seus públicos, para melhorar sua "imagem" e serem bem aceitas, criando condições favoráveis para a venda de seus produtos e serviços, sem uma visão mais ampla do contexto sociocultural.

Agora, com o dossiê "Comunicação, relações públicas comunitárias e terceiro setor", deste número 26 da Organicom-Revista Brasileira de Comunicação Organizacional e Relações Públicas, buscamos reunir contribuições autorais contemporâneas, variadas e interdisciplinares, resultantes de pesquisas bibliográficas (na seção própria do Dossiê) e aplicadas (na seção de Pesquisa), além de uma entrevista com um renomado especialista do campo do terceiro setor. Acreditamos que o conjunto de textos aqui reunidos será de grande valia para promover novas reflexões e novos questionamentos sobre o nosso papel como pesquisadores, professores e profissionais em uma sociedade em constantes transformações.

0 número de papers inscritos para esta edição foi surpreendente. Isto mostra que esse segmento das relações pùblicas vem avançando e ganhando cada vez mais força no Brasil. Tanto no âmbito acadêmico, quanto na esfera pública, na área empresarial e no terceiro setor, as iniciativas estão sendo recorrentes, como revelam os textos selecionados que integram o dossiê. Autores que já produziram livros, capítulos de coletâneas, artigos de periódicos científicos etc. aqui registram suas contribuições com novos olhares e novas abordagens. Com vinte textos, entre pesquisas teóricas, pesquisas empíricas e entrevista, o dossiê certamente será um novo marco na história dos estudos e das práticas das relações públicas comunitárias no Brasil.

\section{Terceiro setor, comunicação e cidadania}

No contexto do dossiê desta edição, damos inicialmente um destaque à entrevista concedida a Pedro Ulsen por Oded Grajew, cofundador e presidente emérito do Instituto Ethos de Empresas e Responsabilidade Social. Para ele, a comunicação é fundamental para organizar movimentos que promovam a cidadania. "Tudo o que fazemos na vida vem de um comando da nossa cabeça, do nosso coração, da nossa mente. A comunicação forma esses conceitos que levam à ação. Ela está no eixo central das organizações".

Diz mais Oded, apontando que é preciso "fazer com que as empresas sejam parte da mobilização, da sensibilização, para melhorar o país". Ele acentua: "Isso significa muita coisa, inclusive aperfeiçoar o nosso sistema democrático, fazer do Brasil uma democracia de verdade. Uma democracia que faça com que o país seja mais justo, com menos desigualdade, mais sustentável e que tenha um modelo sustentável e mais democrático".

A fala de Oded constitui até mesmo um linkpara a seção do Dossiê propriamente dito, onde os temas explorados perpassam aspectos e vertentes focalizados pelo entrevistado, tais como: comunicação, relações públicas, comunidade, esfera pública, cidadania, democracia, mobilização social, responsabilidade social, interesse público, empreendedorismo social etc. São, todos eles, termos infalivelmente presentes quando se abordam na literatura assuntos ligados à comunicação comunitária e participativa e às relações públicas comunitárias.

Cicilia Peruzzo discute parâmetros a partir dos quais as relações públicas com as comunidades e a comunicação organizacional voltadas ao terceiro setor podem ser eticamente desencadeadas pelas organizações identificadas com 0 caráter cívico requerido pelos povos no processo de desenvolvimento histórico. 
Márcio Simeone chama a atenção para a visão das organizações sobre os públicos que elas denominam "comunidades", as ambiguidades e tensões no espaço público frente à atuação dos públicos locais que desencadeia o surgimento emergente de uma nova comunidade, criando uma repartição dos interesses entre esses dois segmentos.

O empreendedorismo social na interface entre comunicação pública e capital social é objeto de análise de Maria José da Costa Oliveira e Silvana Nader, que mostram como a correlação desses conceitos é capaz de apresentar uma opção para 0 desenvolvimento social, no contexto de democracia, sem que se fique atrelado à lógica do mercado.

Regina Escudero aborda aspectos que frequentam a esfera pública da atualidade, onde questões como "novos públicos" que configuram os "novos movimentos sociais" "surpreendem a todos com sua irreverência e complexidade de informação". A autora apresenta uma nova proposta paradigmática, fundamentada na ética da discussão e na comunicação pública.

Fiorenza Carnielli traz reflexões sobre os processos de comunicação pública a partir das instituições, apresentando uma proposta de abordagem da comunicação centrada nas perspectivas normativa, fática e estratégica. Ela busca mostrar como se dá a articulação entre instituição, comunicação pública, comunicação organizacional e estratégia.

Wilson Bueno analisa como a comunicação comunitária desempenha papel fundamental na autoemancipação dos movimentos populares, contribuindo para incrementar sua autonomia e a sua visibilidade. As organizações do terceiro setor utilizam canais e discursos que têm estimulado o debate sobre direitos humanos, sustentabilidade e liberdade de expressão.

Marcelo da Silva, Ellida Guedes e Protásio dos Santos, considerando a necessidade de uma consciência sensível às demandas sociais, discorrem sobre os desafios das relações públicas comunitárias no fomento da participação dos atores sociais para a construção da cidadania, vislumbrando uma sociedade mais igualitária e solidária.

Vanessa Brandão, sob a perspectiva da teoria ator-rede de Bruno Latour, analisa os atravessamentos discursivos entre ONGs, empresas, grupos sociais e ativistas no contexto da atuação da ONU Mulheres Brasil. Ela vê as organizações como atores interagindo em fluxos intermídias estabelecidos com base na temática da igualdade de gênero.

Caroline Kraus Luvizotto Natália dos Santos Gonzales e Renata Calonego, tendo como referência a atuação do Fórum Nacional pela Democratização da Comunicação, refletem sobre a importância da internet e das redes sociais para a mobilização social, a organização, a disseminação e o fortalecimento dos movimentos sociais e dos ativistas.

Vivian Torres, analisando o papel do terceiro setor em ambiente democrático, demonstra que sua atuação tem viabilizado uma participação política de melhor qualidade e com real possibilidade de ingerência no estado, em atendimento aos anseios do cidadão que vive numa sociedade complexa, onde a democracia representativa não mais o atende.

\section{Terceiro setor e comunicação: aportes aplicados}

A seção de Pesquisa, cujos textos constituem aportes aplicados da temática abordada pelo Dossiê, abre com o estudo empírico realizado por Antonio Castillo Esparcia, Margarida M. Krohling Kunsch e Mariângela F. Haswani, sobre 0 papel que a comunicação nas redes sociais digitais desempenha na consecução dos objetivos das organizações nãogovernamentais (ONGs), no Brasil e na Espanha, como estratégia para se tornarem conhecidas, sensibilizar, educar e alcançar legitimação social e política no seio da sociedade. 
Danilo Rothberg e Bruna Giorgi, vendo o acesso à informação pública como um direito fundamental nas democracias contemporâneas, apresentam a pesquisa realizada em portais web governamentais, buscando verificar o potencial da comunicação pública digital para o atendimento do direito à informação sobre políticas públicas para as mulheres no Brasil.

A comunicação comunitária em "não-lugares" compostos por "não-comunidades" norteia a pesquisa de Rodrigo Soares em um conjunto residencial do programa Minha, Casa Minha Vida, em Salvador. 0 sentido de pertencimento nulo dos indivíduos a esse território resulta em um espaço de conflitos em que a comunicação comunitária encontra frágil ancoragem.

Regiane Oliveira Garcêz, mapeando claimsem um grupo de lideranças no Facebook, em uma audiência pública e na Conferência Nacional dos Direitos da Pessoa com Deficiência, debate a noção de representação política discursiva e o uso de fontes de autoridade por lideranças do movimento social dos surdos para buscar legitimidade nos discursos sobre modelos educacionais.

Com a pesquisa para compreender a natureza da comunicação do Fórum Nacional de Prevenção e Erradicação do Trabalho Infantil como instância de mediação, Luíza Mônica Assis Silva e Daniella Rocha Magalhães buscam articular, com base em diversos autores sobre recepção, os saberes do campo organizacional e das instituições da sociedade civil.

Mariana Carareto, Renata Calonego e Roseane Andrelo, analisando as interações dos públicos em campanhas da Skol e da Alezzia no Facebook, refletem sobre a responsabilidade das organizações ao disseminarem seus discursos nas mídias sociais e os impactos sociais dali decorrentes assim como as implicações éticas envolvidas.

Ágatha Paraventi discute os problemas de participação entre organizações e públicos para tomada de decisões, avaliando os modelos pautados no consenso (Grunig), no conflito (teoria construtivista-relacional politicamente responsável - Parc, de Stanley Deetz) e no dissenso (democracia agonística de Mouffe, apresentada por Davidson), adotando o Parc em sua análise.

Lidiane Santos de Lima Pinheiro analisa o discurso da primeira universidade com sistema de cotas do Nordeste, a Universidade do Estado da Bahia (Uneb), observando a construção de seu ethos, seu contrato de comunicação e sua posição de enunciação em campanhas de vestibular, e o compara com o discurso de outra instituição de ensino superior, a Unijorge.

A gestão da humanização hospitalar, tendo como estudo de caso o Hospital Universitário da Universidade de São Paulo, é trabalhada por Maria Aparecida S. Rodrigues e Izabel Cristina Rios, que refletem sobre o conceito da humanização na saúde pública e destacam importância da comunicação como uma aliada para a solução dos desafios nessa área.

\section{Um espaço sempre aberto}

Neste número 26 de Organicom, além do dossiê temático, inserimos seis artigoslivres na seção Espaço aberto, que abordam diferentes temáticas, numa perspectiva internacional, com conteúdos que congregam novas contribuições para a comunicação organizacional e as relações públicas. Além disso, apresentamos duas obras na seção de Resenhas.

Adriana Angel, Lissette Marroquín e Consuelo Vásquez apresentam um mapeamento da comunicação organizacional da América Latina, com base em uma revisão crítica da produção intelectual acadêmica em periódicos científicos, no período 2010-2014, contrastando essa produção com as tendências do campo na Anglo-América. 
LarissaConceição dos Santos e NicoleD'Almeidaavaliam as contribuições daabordagem narrativa/narratológicaà comunicação das organizações. Elas analisam a evolução dessa perspectiva, dos estudos literários até sua introdução no domínio das ciências humanas e sociais, destacando, especialmente, a abordagem narratológica da comunicação organizacional.

Para fundamentar a conexão e a convergência entre a educomunicação e a comunicação organizacional, Larissa B. Rigo, Ivana de Jesus Gehlen, Marcelo Tavares e Keynayanna K. Fortaleza, com base em diversos autores, desvelam a relação entre os conceitos e as práticas da educomunicação e da comunicação nos ambientes organizacionais.

Márcio Simeone Henriques e Daniel Reis Silva abordam a experiência do "jogo das relações públicas", uma atividade lúdica de simulação e interpretação de papéis concebida para auxiliar a compreensão das complexas dinâmicas que permeiam a atividade de relações públicas, assim como a relação entre jogos de simulação e ensino.

O entrelaçamento entre as percepções de Rudimar Baldissera sobre a comunicação organizacional e as estruturas de participação de Erving Goffman é analisado por Dôuglas A. Ferreira e Ivone de L. Oliveira, pelo estudo de um jornal interno de uma empresa, vendo como se processam as representações de papéis e as estratégias de interação entre trabalhadores.

Fechando a seção, Ivone Ferreira e José Gabriel Andrade analisam, com base em pesquisa da Associação Portuguesa para os Direitos do Consumidores, o pouco conhecimento e a imagem que os portugueses têm em relação ao Fundo Monetário Internacional, mesmo figurando este entre as instituições de que eles mais ouviram falar, através da mídia, nos últimos anos.

Com a intenção de disseminar e compartilhar obras diferenciadas recentemente publicadas, registramos as resenhas de dois ivros: Reputação, norma, ativo, confiança e gestão virtuosa integradora e as interpretações dos sujeitos: capital, comunicação e virtual coletivo, de Ana Lucia de Alcântara Oshiro, resenhado por Marta Terezinha Motta Campos Martins; e Relações públicas na contemporaneidade: contexto, modelos e estratégias, de Bianca Marder Dreyer, resenhado por Else Lemos.

\section{A responsabilidade social na construção de um país justo e sustentável}

Valemo-nos do título da entrevista com Oded Grajew para assinalar que os conteúdos explorados no dossiê nos levam a considerar que os novos tempos exigem que o profissional de relações públicas tenha uma visão muito crítica, engajando-se em projetos de mobilização social com base científica e ao mesmo tempo inserindo-se no jogo da produção social.

No trabalho de parceria entre o público e o privado, a área de relações públicas poderá desempenhar um importante papel. Por meio do ou junto com o terceiro setor, ela poderá promover mediações entre o estado e a iniciativa privada, repensando o conteúdo, as formas, as estratégias, os instrumentos, os meios e as linguagens das ações comunicativas com os mais diferentes grupos envolvidos, a opinião pública e a sociedade como um todo.

É necessário que se reconheça a força e o poder da sociedade civil, nos processos de participação cidadã, mediante a atuação dos movimentos organizados e das ONGs. Sua função é, sobretudo, exercer um papel influenciador da mudança do status quo, do poder do estado e do mercado, no atendimento das demandas emergentes - locais, nacionais, regionais e globais -, no campo dos direitos à cidadania e aos valores sociais. 
São inúmeras as possibilidades de mediações. Elas estão presentes no primeiro e no segundo, mas, sobretudo, no terceiro setor, que compreende um vasto campo de atuação - ONGs; fundações; associações e institutos que se dedicam a melhorar a vida das pessoas, a atender crianças, adolescentes e idosos desprotegidos, portadores de deficiência, famílias carentes ou em situação de risco, refugiados, presos, minorias raciais e muitos outros grupos esquecidos pelo poder público e pela sociedade em geral.

A responsabilidade social e a cidadania corporativa, tão presentes no discurso empresarial, não podem ser vistos tão somente como instrumentos a serviço de ganhos mercadológicos e de imagem institucional. Nem, muito menos, como mais um modismo ou uma bandeira de luta. As organizações devem mostrar que assumem de fato uma prática responsável e comprometida com a melhoria da qualidade de vida das pessoas e a diminuição das desigualdades sociais. As relações públicas têm um papel importante nesse contexto. Só assim elas estarão cumprindo sua função social, ao lado de outras funções estratégicas.

Com mais esta edição de Organicom, esperamos estar contribuindo para o aprofundamento dos estudos e das práticas da comunicação e das relações públicas comunitárias numa perspectiva eminentemente, social, democrática, interdisciplinar e integrada, com vistas a uma intervenção salutar na sociedade e a uma formação mais crítica de todos os atores envolvidos no meio acadêmico e nas práticas cotidianas das instituições públicas e das organizações em geral. Desejamos a todos uma boa leitura. 